\title{
Sexual Behaviour of Congolese Teenagers
}

\section{Lucie Charlotte Ollandzobo Ikobo ${ }^{1,2 *}$, Steve Vassili Missambou Mandilou2, Messie Josias Matsielo', Lynda Tchidjo Ngamo', Evrard Romaric Nika², Jean Robert Mabiala Babela1,2}

\author{
${ }^{1}$ Faculté des Sciences de la Santé, Université Marien Ngouabi, Brazzaville, Congo \\ ${ }^{2}$ Service de pédiatrie nourrisson, CHU de Brazzaville, Brazzaville, Congo \\ Email: *lucieatipo@hotmail.fr
}

How to cite this paper: Ollandzobo Ikobo, L.C., Missambou Mandilou, S.V., Matsielo, M.J., Tchidjo Ngamo, L., Nika, E.R. and Mabiala Babela, J.R. (2021) Sexual Behaviour of Congolese Teenagers. Open Journal of Pediatrics, 11, 656-668.

https://doi.org/10.4236/ojped.2021.114061

Received: October 1, 2021

Accepted: December 4, 2021

Published: December 7, 2021

Copyright $\odot 2021$ by author(s) and Scientific Research Publishing Inc. This work is licensed under the Creative Commons Attribution International License (CC BY 4.0).

http://creativecommons.org/licenses/by/4.0/ Open Access

\begin{abstract}
Introduction: Sexual risk behaviour among adolescents is a public health problem worldwide. Widely studied in the Western countries, this problem has only been addressed partially in Brazzaville. Thus, 12 years later, we conducted this study with the aim of analysing the sexual behaviour of adolescents in Congo. Patients and Methods: This was a cross-sectional and analytical study from January to August 2019 (8 months). It involved 2000 adolescents residing in the departments of Brazzaville and Pointe-Noire constituting the urban population, and those of Cuvette and Bouenza, the rural population. Results: A total of 1167 adolescents reported being sexually active. The mean age at first sexual intercourse differed between the two sexes $(\mathrm{p}<0.0005)$. Of the adolescents surveyed $96.1 \%(\mathrm{n}=1122)$ claimed to have ever heard of HIV/AIDS infection and $8.7 \%(\mathrm{n}=101)$ to have ever contracted sexually transmitted infections. The main channel of information was school in $57.7 \%$. Condoms were the only means of protection (85.5\%). The factors associated with risky sexual behaviour were, on the one hand, those related to the adolescent (lack of schooling, orphan status, alcohol and tobacco consumption, paid employment and possession of a mobile phone). On the other hand, those related to parents (low level of education, mother's employment status and single-parent household structure). The frequency of sexually active adolescents was similar in both settings $(\mathrm{p}<0.05)$. The rates of adolescents having ever heard of HIV/AIDS were almost similar with a slight predominance in urban areas $(\mathrm{p}<0.09)$. Early sexual intercourse $(72.6 \%)$ and/or multiple partners $(24.9 \%)$ were more frequent in rural areas $(\mathrm{p}>0.05)$. Homosexuality was found in $4.6 \%$ in urban areas and $3.8 \%$ in rural areas ( $p>$ $0.05)$. Extra-vaginal sex accounted for $16.4 \%$ in urban areas and $7.9 \%$ in rural areas $(\mathrm{p}=0.001)$. Non-consensual sex was more common in urban areas $(17.4 \%)$ than in rural areas $(5.8 \%)(\mathrm{p}=0.001)$. Incestuous sex was reported in $6.2 \%$ of cases (urban) and $4.2 \%$ (rural) ( $\mathrm{p}>0.05)$. Conclusion: Sexual risk behaviour is real among adolescents in the Congo. The advanced moderniza-
\end{abstract}


tion marked by the abundance of mass media in urban areas favours the predominance of these behaviours in the city. The consequences are serious and can compromise the future of adolescents; hence the importance of prevention.

\section{Keywords}

Adolescent, Risky Sexual Behaviour, Congo

\section{Introduction}

Adolescence is a period of life that marks the gradual transition from childhood to adulthood, is accompanied by physical, biological and psycho-emotional transformations that lead to profound changes, particularly in sexual behaviour. Sexual behaviour is conduct aimed at the satisfaction of sexual pleasure; it is said to be "risky" when it exposes adolescents to serious and sometimes dramatic consequences [1]. According to the WHO, sexual risk behaviour (SRB) in adolescence is a worldwide concern and a real public health problem [2]. In the West, this widely studied issue shows a significant reduction in the rate of SRB in adolescent populations [3] [4]. In Africa, SRB is likely to lead to multiple complications in adolescents considered as "immature", such as sexually transmitted infections (STIs) including HIV/AIDS, early and unwanted pregnancies with all their consequences [5] [6]. In Congo, after a piecemeal study carried out 12 years ago in Brazzaville, we conducted this study with the aim of analysing the sexual behaviour of adolescents in Congo. More specifically, to describe adolescent sexual behaviour at the national level, to identify factors associated with RSB in adolescents and to assess the influence of place of residence on the sexual behaviour of Congolese adolescents.

\section{Materials and Methods}

This is a cross-sectional, descriptive and analytical study conducted from January to August 2018 (8 months). It was conducted in four (two urbans and two rurals) of the country's 12 departments. The sampling method was a randomized two-stage cluster survey, stratified by sex and residence borough or district. The sample was drawn from households in the selected boroughs or districts of the departments. Adolescents in Brazzaville and Pointe-Noire (the most populated departments of the country as they account for more than $60 \%$ of the national population [7]) constituted the urban population, and those in Bouenza and Cuvette (selected randomly because of their demographic similarities) the rural population. For each borough (urban area), all neighborhoods were identified and each neighborhood constituted a cluster. The selection of clusters was done by a simple random draw. A total of 30 clusters were selected for the study and distributed proportionally to the size of each borough. Using the map of the de- 
partments, the boundaries and centers of each selected cluster were identified. From the center of the cluster, the direction of travel was randomly selected. The first plot was selected by a simple random draw among those counted in the center of the cluster. Then, one plot out of five was selected, once to the right and once to the left. At the intersection of two streets the choice of the next direction was made by the same process. Thus, in each household, only one adolescent aged 10 to 19 was interviewed. A total of 1560 adolescents (900 in Brazzaville and 660 in Pointe-Noire) were included. In the rural area, for each district all villages were identified and each village constituted a cluster. The selection of clusters per sample was done by simple drawing. A total of 30 clusters were selected and distributed in proportion to the size of each village. The limited budget did not allow us to visit all the districts of the two departments. Thus, one district per department was selected randomly. For Bouenza it was the district of Kayes and for Cuvette the district of Boundji. In each household, only one adolescent aged 10 to 19 was interviewed. A total of 440 adolescents were interviewed (220 in Cuvette and 220 in Bouenza). In all cases, parental or legal guardian permission was required to participate in the study. Adolescents who agreed to answer the questionnaire objectively, after obtaining parental permission, were included in the study. We excluded adolescents whose parents or guardians did not consent, and those who did not complete the questionnaire.

Data were collected by the same investigators at the different study sites using a pre-designed survey form. The survey form was designed by the research team in consultation with the statistician. Of note, these data were taken from a research dissertation submitted to the faculty of health sciences of Brazzaville as part fulfilment of award of diploma of doctorate in medicine. For each adolescent who met the inclusion criteria, the variables studied were socio-demographic; firstly, in relation to the child (age, sex, religious practice, schooling, marital status, place of residence, social status, paid employment, existence of a mobile phone), secondly in relation to the parents (level of education, employment status, household structure). Qualitative variables related to sexual behaviour (first sexual intercourse, knowledge and use of means of protection against STIs, sexual orientation, sexual violence, sexual practice) and quantitative variables (age at first sexual intercourse, number of partners) were also taken into account.

The statistical analysis was done with Microsoft Excel version 2013 and Epi info version 7.1.1.1. The results were expressed as mean and standard deviation for quantitative variables and as headcount or percentage for qualitative variables. The Pearson chi-square test was used to compare the rates with significance if $\mathrm{p}<0.05$ and a $95 \%$ confidence interval (CI).

\section{Results}

In total two thousand adolescents were included, with a M/F ratio of 0.84 . Adolescents were aged from 10 to 19 years; divided into two groups according to age. From 10 - 14 years, boys $(n=200 ; 46.19 \%)$ and girls $(233 ; 53.81 \%)$ and from $14-19$ 
years, boys $(\mathrm{n}=712 ; 45.44 \%)$ and girls $(\mathrm{n}=855 ; 54.56 \%)$. The socio-demographic characteristics of the adolescents surveyed are shown in Table 1, and those of the parents of the adolescents surveyed are shown in Table 2.

Of the adolescents surveyed, 1167 claimed to be sexually active, a frequency of $58.4 \%$. The mean age of first sexual intercourse differed between the two sexes ( $p$ $<0.0005$ ). It was $14.6 \pm 1.8$ years (extremes $10-19$ ) for boys and $15.5 \pm 1.4$ years (extremes 13 - 19) for girls. Among the adolescents surveyed, 96.1\% ( $\mathrm{n}=1122$ )

Table 1. Socio-demographic characteristics of the adolescents surveyed.

\begin{tabular}{|c|c|c|}
\hline & Frequency (n) & Percentage (\%) \\
\hline \multicolumn{3}{|l|}{ Gender } \\
\hline Male & 912 & 45.6 \\
\hline Female & 1088 & 54.4 \\
\hline \multicolumn{3}{|l|}{ Education } \\
\hline Enrolled in school & 1844 & 92.2 \\
\hline Unschooled & 23 & 1.2 \\
\hline Drop out & 133 & 6.6 \\
\hline \multicolumn{3}{|l|}{ Religious practices } \\
\hline Yes & 1701 & 85.1 \\
\hline No & 299 & 14.9 \\
\hline \multicolumn{3}{|l|}{ Marital status } \\
\hline Matrimonial home & 154 & 7.7 \\
\hline Under parental roof & 1846 & 92.3 \\
\hline \multicolumn{3}{|l|}{ Social status } \\
\hline Orphans & 296 & 14.8 \\
\hline Non orphans & 1704 & 85.2 \\
\hline \multicolumn{3}{|l|}{ Paid employment } \\
\hline Yes & 240 & 12 \\
\hline No & 1760 & 88 \\
\hline \multicolumn{3}{|l|}{ Alcohol consumption } \\
\hline Yes & 766 & 38.3 \\
\hline No & 1234 & 61.7 \\
\hline \multicolumn{3}{|l|}{ Tabacco consumption } \\
\hline Yes & 150 & 7.5 \\
\hline No & 1850 & 92.5 \\
\hline \multicolumn{3}{|l|}{ Mobile phone owner } \\
\hline Yes & 1248 & 62.4 \\
\hline No & 752 & 37.6 \\
\hline \multicolumn{3}{|l|}{ Place of residence } \\
\hline Urban area & 1560 & 78 \\
\hline Rural area & 440 & 22 \\
\hline
\end{tabular}


Table 2. socio-demographic characteristics of the adolescents' parents.

\begin{tabular}{lcc}
\hline & Frequency (n) & Percentage (\%) \\
\hline Level of instruction & 778 & 38.90 \\
Unschooled & 1369 & 68.45 \\
Primary & 1188 & 59.40 \\
Secondary & 665 & 33.25 \\
Higher & & \\
Occupational status & 773 & 38.55 \\
Unemployed & 113 & 5.65 \\
Retired & 1718 & 81.9 \\
Unskilled work & 1396 & 68.8 \\
Skilled work & & 77.7 \\
Household structure & 1554 & 14.4 \\
Biparental & 288 & 7.9 \\
Monoparental & 158 & \\
Homeless & &
\end{tabular}

said they had ever heard of HIV/AIDS infection and 8.7\% $(\mathrm{n}=101)$ had ever contracted an STI. The channel of information was school in $57.7 \%$ of cases, the media in $18 \%$, peer talk in $12.3 \%$ and the parental home in $12 \%$ of cases. Of these, $14.3 \%(n=274)$ claimed to have received routine HIV testing. The male condom was the only means of protection against STIs and HIV/AIDS in $85.5 \%$ of cases. The adolescents surveyed claimed to have had sex with several partners in 260 cases with $\mathrm{p}<0.001$ (boys $=67.3 \%$ and girls $=32.7 \%$ ). The practice of sexual relations among adolescents of the same sex was found in $3.9 \%(n=45)$ of cases. These were girls in 33 cases and boys in 12 cases. During this survey, $14.7 \%(\mathrm{n}=171)$ of adolescents claimed to have had extra-vaginal sex; $56.7 \%$ were girls and $43.3 \%$ were boys. In $15 \%(n=175)$ of cases, adolescents admitted to having had non-consensual sex. Girls were involved in $69.7 \%$ of cases and boys in the remaining cases. Incestuous sexual relations were found in $5.7 \%(\mathrm{n}=$ 67) of adolescents (boys $n=47$; girls $n=20$ ); and the sexual act had taken place in almost all cases under the family roof and without the knowledge of parents or guardians. The distribution of incest cases according to the nature of the partner (Figure 1).

The factors associated with risky sexual behaviour were related to adolescents or to parents. Those related to female adolescents were: possession of a mobile phone ( $\mathrm{p}=0.001$; OR [CI 95\%]: 10.1 [2.7 - 47.4]), alcohol consumption ( $\mathrm{p}=$ 0.02; OR [CI 95\%]: 2.33 [1.068 - 5.11], orphan status ( $\mathrm{p}=0.005$; OR [CI 95\%]: $2.0[1.3-3.3])$ and a paid employment $(\mathrm{p}=0.003$; OR [CI 95\%]: 2.1 [1.3 - 3.3]. The factors associated with risky sexual behaviour in male adolescents were: possession of a mobile phone ( $\mathrm{p}=0.001$; OR [CI 95\%]: 5.6 [2.6 - 12.6]), alcohol consumption ( $\mathrm{p}=0.001$; OR [CI 95\%]: 4.5 [2 - 10.5]) and tobacco consumption 
$(\mathrm{p}=0.02$; OR [CI 95\%]: 6.509 [2.02 - 20.95]). Those related to their parents were: the low level of education ( $\mathrm{p}=0.02$; OR [CI 95\%]: $2.4[1.2-5.3])$, the mother's professional status $(\mathrm{p}=0.003$; OR [CI95\%]: 3.6 [1.6 - 9.5]), and the single parent family ( $\mathrm{p}=0.032$; OR [CI 95\%]: 7.7 [1.5 - 160.2]). The comparison of sexual practices of adolescents according to place of residence is shown in $\mathrm{Ta}$ ble 3.

\section{Discussion}

First of all, it is important to note that comparing the results of this study with those of other authors must be done with caution because of methodological differences. Indeed, the interrogative method used involves certain hazards insofar as it relies on the good faith of the respondent; in this case, the adolescent may voluntarily provide a false negative answer in order to hide a reprehensible response (even if anonymity has been previously guaranteed). However, this method does not offer any alternatives. Another possible cause of over-reporting of sexual behavior could be the boastfulness or braggart of adolescents, but we agree with Morris et al. [8] that anonymity and the use of a questionnaire made

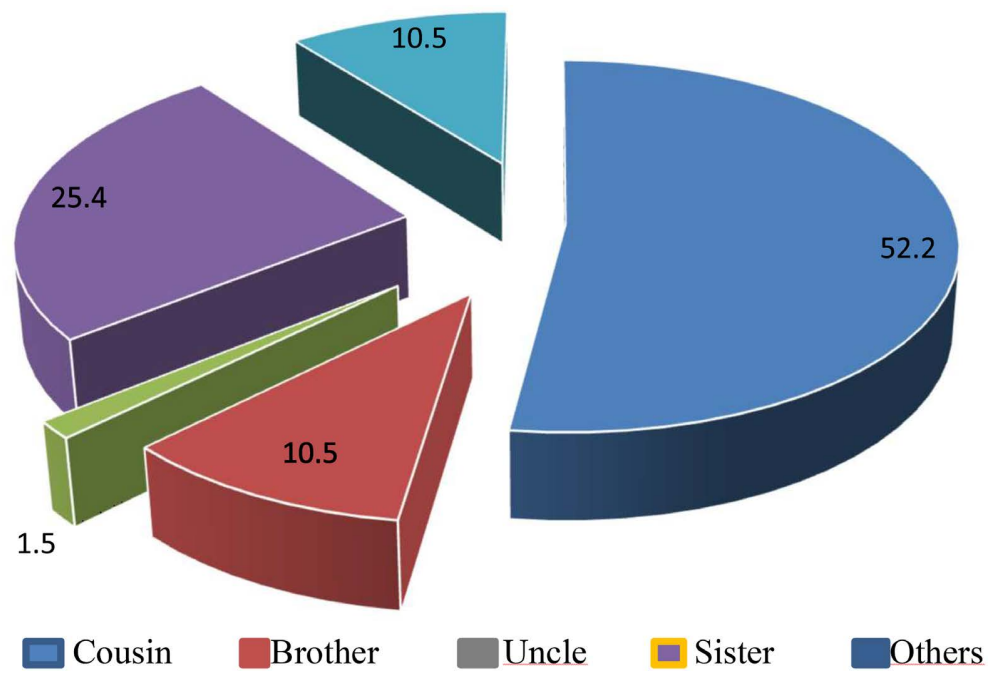

Figure 1. Distribution of incest cases according to the nature of the partner.

Table 3. Sexual practices of adolescents and place of residence

\begin{tabular}{cccccc}
\hline & \multicolumn{2}{c}{ Urban } & \multicolumn{2}{c}{ Rural } & \multirow{2}{*}{$\mathbf{p}$} \\
\cline { 2 - 5 } & $\mathbf{n}$ & $\%$ & $\mathbf{n}$ & $\%$ & \\
\hline Same sex intercourse & 34 & 4.6 & 11 & 3.8 & 0.650 \\
Extra-vaginal intercourse & 152 & 16.4 & 19 & 7.9 & 0.001 \\
Non-consensual sex & 161 & 17.3 & 14 & 5.81 & 0.000 \\
Incestuous sexual intercourse & 57 & 6.2 & 10 & 4.2 & 0.297 \\
Early sexual intercourse & 590 & 63.7 & 175 & 72.8 & 0.024 \\
Multiples partners & 200 & 21.6 & 60 & 24.9 & 0.3129 \\
\hline
\end{tabular}


this unlikely. Beyond these few shortcomings, the current study included both in-school and out-of-school adolescents, was conducted in Brazzaville, Pointe Noire (the two most populated departments of the country) and in two other departments based on the departmental distribution of the Congo Demographic Health Survey (EDSC) [7]; giving it a national character; helping to have a global vision of the problem, and leading to inclusive preventive measures. In contrast to other studies previously conducted in the country on the field but that considered only adolescent girls or in-school children/adolescents and were limited to Brazzaville [6] [9] [10].

Today's increasingly liberated sexual behaviour among adolescents seems to defile the morality of abstinence until marriage. Several reasons have been put forward to explain the high proportion of adolescents who have sexual relations at an early age [11]: the erotic and sexual explosion in the media (television and cinema with the broadcasting of pornographic films, radio, internet, smartphone) which now play a major role in the education of young people and encourage them to engage in certain sexual practices. Similarly, physical maturation is always accompanied by a surge in sexual impulses with a desire for affirmation and a great thirst for discovery of the other sex; the lack of distinction in sexual activity between procreation and pleasure.

In this study $58.4 \%$ of adolescents declared to be sexually active. This prevalence is similar to that of Mabiala Babela et al. [6] who found a frequency of $52.7 \%$. On the other hand, Grondin et al. [12] reported a rate of $40.3 \%$ which is lower than ours. This result could be explained by methodological differences in the choice of the study population.

The mean age at first sexual intercourse differed between genders. Sexual activity was earlier in boys (14.6 years) compared to girls ( 15.5 years) with a highly significant difference $(\mathrm{p}<0.001)$. Male precociousness was also found by Mabiala Babela et al. [6] in Brazzaville. Masmoudi-Soussi et al. [13] in Tunisia found a mean age of 16.5 years. This difference could be explained by the particularity of their study population, which included university students. However, the weight of habits and customs should not be neglected in the occurrence of first sexual relations. The conditions and lifestyles are also often mentioned to explain this new behaviour, as the environment in which adolescents live is subject to numerous changes (media, television, cinema) influencing their sexual behaviour. Moreover, the study by Udry et al. [14] on the links between "age, hormones, pubertal development" and sexual response in adolescence, reports a differential effect according to sex. In boys, the main determinant of the onset of sexual intercourse is the rise in hormonal (androgen) concentrations during puberty. It can therefore be assumed that an early-maturing boy is more prone to sexual initiation. On the other hand, according to the same authors, androgens have a direct effect on certain sexual behaviours (masturbation, subjective sexual experiences) in girls, but not on the first sexual relations. This would explain in part the predominance $(p<0.001)$ of boys having had their first sexual inter- 
course. The use of protective methods against STIs remains low among adolescents, despite the increase in awareness campaigns and STI education in schools. In this survey, almost all adolescents (96.1\%) were informed about HIV/AIDS via school and media, the main channels of information; however, voluntary testing for HIV infection remains less frequent. The fear of testing positive is the main reason for this mistrust, as well as the immaturity of adolescents.

Sexual risk behaviour (SRB) such as multiple partner sex, homosexuality, extra-vaginal sex, non-consensual sex and incest are a reality in this study. Indeed, sex with multiple partners was more common among boys (67.3\%) than in girls (32.7\%). These findings are similar to those of Adbulkarim et al. in Nigeria [5], who found rates of $69.3 \%$ and $31.7 \%$ respectively in boys and girls, and those of Marceli et al. in France [3] who reported 27\% among girls. However, Mabiala Babela et al. [6] reported a much higher rate of 51.1\% among girls in Brazzaville. This difference can be explained by the economic and socio-political context of the country in this post-conflict period, where $24.1 \%$ of adolescent girls used sex for economic reasons [6]. The high rate of sex with multiple partners more frequently observed among boys in our study could necessarily be linked to other risk factors, notably a paid job, the fact of having a mobile phone, alcohol and tobacco consumption, and the mother's professional situation.

Being interviewed on sexual orientation can be a source of anxiety and shame, especially in our society. In our study, homosexual activity with or without penetration was found in 45 (3.9\%) adolescents, mostly girls (2.8\%) compared to boys (1.1\%). Khemakhem et al. [15] in Tunisia found the same trend, with a higher frequency of $15.4 \%$ for adolescent girls and $11.5 \%$ for adolescent boys. This difference can be explained by the fact that this "shameful" practice remains taboo in our country, which is strongly anchored in religion and under the weight of tradition. Moreover, this activity is much more a matter of discovery than of real identification with the other sex.

Among sexually active adolescents, $14.1 \%$ practised extra-vaginal sex, with a female predominance (56.7\%). To our knowledge, no study has been conducted in this regard among adolescents in Congo. However, several factors related to this practice have been found: the parents' professional situation, single-parent home and alcohol consumption in girls, while social status, telephone ownership, alcohol consumption and smoking were predominant in boys. In our study, non-consensual sex was essentially studied in terms of victimisation. Thus, $15 \%$ of the adolescents surveyed were victims of non-consensual sex, the majority being girls (69.7\%) compared to boys (30.1\%). This result is similar to that of De Graaf et al. [16], 18.5\% of which one in four girls and one in ten boys, and that of Glowacz et al. [17], who reported 11.9\% among adolescent girls. The lack of experience and the intensity with which adolescents experience their first romantic relationships may lead them to commit or tolerate certain acts of violence [18] and sexual coercion [19] [20] [21].

Incestuous sex, found in $5.7 \%$ of this study, was a more frequent practice 
among girls. No particular comment can be made with regard of these findings due to the lack of data on the field in the literature.

Comparing the sexual behaviour of urban and rural adolescents in this study, we found a similar frequency of sexually active adolescents in both settings. The rates of adolescents having heard of HIV/AIDS are almost identical, with a slight predominance in urban areas. Sexual risk behaviour such as early sex and/or sex with multiple partners are more common in rural than in urban areas, while homosexuality, incestuous sex, non-consensual sex and extra-vaginal sex are more common in urban areas. The abundance and effect of the mass media, more predominant in the city, certainly justifies this difference.

Finally, these findings support the need to address this problem through serious and high-quality sexual health education and prevention services in other to improve adolescent sexual health outcomes, especially in the early adolescent. Several models engaging adolescents in sexual health, including education counseling, cultural, social and spiritual interventions, and computer program could be implemented, as they have been proven to be efficient [22]. Another component that should be taken into account when addressing this issue is that parents, peers and teachers are important human resources of influence on adolescent' sexual behaviors that should not be left aside.

\section{Conclusion}

Sexual risk behaviour is real in the Congo, both in rural and urban areas. The advanced modernisation marked by the abundance of mass media in urban areas favours the predominance of these behaviours in the city. The consequences are serious and can compromise the future of adolescents; hence the importance of prevention, which involves setting up a national programme to fight against the risk factors, coupled with sex education.

\section{Conflicts of Interest}

The authors declare no conflicts of interest regarding the publication of this paper.

\section{References}

[1] Sultan, C. (1999) Normal Puberty: Recent Data. Real pediatrics, 44, 6-10.

[2] World Health Organization (2009) Teenage Pregnancy, a Complex Cultural Issue. Bulletin of the World Health Organization, 87, 405-484. https://doi.org/10.2471/BLT.09.000609

[3] Marcelli, D. (2010) Sexuality of Children in Their Latent Years. Between Education and Seduction: What Fate for the Impulses? Child and Adolescent Neuropsychiatry, 58, 60-63.

[4] Cardéac d'Arbaud, B. (2010) Adolescent Sexuality: Listening, Information on the Phone and on the Internet. Archive of Pediatrics, 17, 928-929.

[5] Adbulkarim, A.A., Mokuolu, O.A. and Adeniyi, A. (2003) Sexual Activity among Adolescents in Horin, Kwara State, Nigeria. African Journal of Medicine and Medi- 
cal Sciences, 32, 339-341.

[6] Mabiala Babela, J.R., Massamba, A., Bantsimba, T. and Senga, P. (2007) La sexualité de l'adolescent à Brazzaville, Congo. Journal of Gynecology Obstetrics and Reproductive Biology, 37, 510-515. https://doi.org/10.1016/j.jgyn.2007.11.033

[7] National Centre of Statistics and Economics Studies (2005) Enquête démographique et de santé du Congo (EDSC).

[8] Morris, L., Warren, C.W. and Aral, S.O. (1993) Measuring Adolescent Sexual Behaviours and Related Health Outcomes. Public Health Reports, 108, 31-36.

[9] Iloki, L.H., Koubaka, R., Itoua, C. and Mbemba Moutouno, G.M. (2004) Pregnancy and Childbirth in Adolescents in the Congo. 276 Cases at the University Hospital of Brazzaville. Journal de Gynecologie, Obstetrique et Biologie de la Reproduction, 33, 37-42. https://doi.org/10.1016/S0368-2315(04)96310-7

[10] Kamtcouing, P., Takouang, I., Ngoh, N. and Yakam, I. (1997) Adolescent Sexuality in Schools in Yaoundé. Contracept Fertil Sex, 25, 798-801.

[11] Kuyper, L., de Wit, J., Smolenski, D., Adam, P., Woertman, L. and van Berlo, W. (2013) Gender Differences in Patterns of Experienced Sexual Coercion and Associated Vulnerability Factors among Young People in the Netherlands. Journal of Interpersonal Violence, 28, 3149-3170. https://doi.org/10.1177/0886260513488689

[12] Grondin, C., Duron, S., Robin, F., Verret, C. and Imbert, P. (2013) Adolescents' Knowledge and Behaviour Regarding Sexuality, Sexually Transmitted Infections and Human Papillomavirus Vaccination: Results of a Cross-Sectional Survey in a High School. Archive of Pediatrics, 20, 845-852. https://doi.org/10.1016/j.arcped.2013.05.012

[13] Masmoudi-Soussi, J., Bellaaj-Lachtar, F., Aloulou-Bouguecha, J., Amami, O., Halouani, A. and Jarraya, A. (2006) Sexual Life of Tunisian Adolescents. Annales Médico-Psychologiques, 164, 395-401. https://doi.org/10.1016/j.amp.2004.12.003

[14] Udry, J.R., Talbert, L.M. and Morris, N.M. (1986) Biosocial Foundations for Adolescent Female Sexuality. Demography, 23, 217-230. https://doi.org/10.2307/2061617

[15] Khemakhem, R., Homri, W., Bram, N., Ben Romdhane, I. and Labbane, R. (2016) Sexuality of Tunisian Adolescents. Sexologies, 26, 74-78.

[16] De Graaf, I., De Haas, S., Zaagsma, M. and Wijsen, C. (2015) Effects of Rock and Water: An Intervention to Prevent Sexual Aggression. Journal of Sexual Aggression, 22, 4-19. https://doi.org/10.1080/13552600.2015.1023375

[17] Glowacz, F., Goblet, M. and Courtain, A. (2018) Sexual Coercion in Adolescence: From Non-Consensual to Sexuality under Constraint. Sexology, 27, e33-e37. https://doi.org/10.1016/j.sexol.2018.02.010

[18] Benbouriche, M. and Parent, G. (2018) Sexual Coercion and Sexual Violence in the General Population: Definition, Available Data and Implications. Sexologies, 27, 81-86.

[19] French, B.H., Tilghman, J.D. and Malebranche, D.A. (2015) Sexual Coercion Contextand Psychosocial Correlates among Diverse Males. Psychology of Men \& Masculinities, 16, 42-53. https://doi.org/10.1037/a0035915

[20] Spitzberg, B.H. (1999) An Analysis of Empirical Estimates of Sexual Aggression: Victimization and Perpetration. Violence and Victims, 14, 241-260. https://doi.org/10.1891/0886-6708.14.3.241

[21] Williams, C.M., Cook-Craig, P.G., Bush, H.M., Clear, E.R., Lewis, A.M., Garcia, L.S., et al. (2014) Victimization and Perpetration of Unwanted Sexual Activities 
among High School Students: Frequency and Correlates. Violence against Women, 20, 1239-1357. https://doi.org/10.1177/1077801214551575

[22] Chokprajakchad, M., Phuphaibul, R. and Sieving, R.E. (2018) Sexual Health Interventions among Early Adolescents: An Integrative Review. Journal of Health Research, 32, 467-477. https://doi.org/10.1108/JHR-04-2018-0004 
Survey Form N: /.........../

\section{Sexual Behaviour of Congolese Teenagers}

Date: $/ \ldots . . / \ldots . . . / \ldots . . . /$

\section{GENERAL INFORMATION}

1. Gender

Male: $/$......./ Female: /......../

2. Date of birth

3. Age

4. Mailing address

5. Are you able to read?

Yes: /........./

Catholic: /

Single: /
No: /........../

Protestant: /......../

Married: /........../
Muslim: /.

Divorced:
Other: /. /

\section{PAST MEDICAL HISTORY}

1) Gynecology

8. Age at menarche

9. Duration of menstrual cycle

10. Duration of menstruation

11. Have you ever had surgery?

Yes: /........../

No: /........../

If yes, give the reason: /........../

\section{2) Obstetrics}

12. Do you have children?

Yes: /........./

No: /........../

If yes, how many: /........./

\section{3) Habits}

13. Do you drink alcohol?

14. Do you smoke?

Yes: /........../

Yes: /........../

No: $/ \ldots \ldots \ldots \ldots /$
No: $/ \ldots \ldots \ldots . . . /$

\section{EDUCATION AND SOCIOECONOMIC STATUS}

\section{1) Education}

15. Do you attend school? If yes

16. At which level?

17. In which sector?

If no

18. Why?

19. Did you drop out of school?

If yes, why?

If yes, at which level?

20. Do you have a paid work?

\section{2) Socioeconomic status}

21. Number of children in the family

22. Father Age: /......./ Profession: /....../ Level of education:/......../ Died: /....../

23. Mother Age: /......./ Profession: /...../ Level of education:/......./ Died: /....../

24. Marital status of parents Divorced:/..... / Live together: /...... /
Yes: $/ \ldots \ldots \ldots . / \quad$ No: $/ \ldots \ldots \ldots . . /$

Primary:/...../ Secondary:/..../ University:/...../

Public: /...../ Private: /...../

Yes: $/ \ldots \ldots \ldots . . / \quad$ No: $/ \ldots \ldots \ldots . . /$

Yes: $/ \ldots \ldots \ldots . . / \quad$ No: $/ \ldots \ldots \ldots . . /$ 


\section{PUBERTY AND SEXUALITY}

25. Have you ever had sex?

Yes: /........../

No: / .........../

26. Since the first time, how many partners have you had sexwith?

27. How old were you the first time you had sex?

28. Currently, how many partners regularly have sex with you?

29. Have you ever heard of contraception? Yes: /........../

No: /.........../

30. If yes, where? At school: /....../ By friends: / ......./ Via media: /....../

31. Have you ever used a contraceptive method?

Yes: /........../

By parents: / ......./

32. If yes, which one? Condoms: /...../ Pills:/...../

Ogino Method: / ......

No: /.........../ Girl

33. Have you been pregnant before?

Yes: /........../

No: / .........../

Boys

34. Have you ever pregnant a woman?

Yes: /........../

No: /........../

35 . Have you ever had sex with people of the same sex as you?

36. Have you ever had extra-genital sex? Yes: /........./

37. Have you ever had non-consensual sex? Yes: /........../

38. Have you ever had incestuous sex? If so, with whom?

39. Have you ever had a sexually transmitted infection (STI)?

40. If so, how many times?

41. At what age did you first get an STI?

42. Did you have a treatment?

43. If yes, did you consult a health care professional?

44. Did you buy the medication at the pharmacy?

45. Have you ever heard of AIDS?

Yes: /........../

No: /.........../

No: $/ \ldots \ldots \ldots . . . /$

No: /.........../

Yes: /.........../

Yes: /.........../

No: / .........../

No: /........../

46. If yes, where? By parents: /....../ By school: /....../

47. Have you ever been tested for AIDS?

\section{PREGNANCY}

48. At what age did you have your first pregnancy?

49. Was the pregnancy wanted?

Yes: /........../

No: /........../

50. Did you drop out of school because of the pregnancy?

Yes: /.

No: /............/

51. Have you ever had an abortion?

Yes: /........../

No: /.........../

52. If yes, why

53. If yes, by which method?

54. If yes, how many times?

55. Who was the perpetrator? Teacher: /......./

Parents: /....../

Friend of Parents: /...../ Other: /......../ 